D.J. Schipper and A.W.J. de Gee Department of Mechanical Engineering, University of Twente, Enschede, The Netherlands

\section{Lubrication Modes and the IRG Transition Diagram}

\section{Abstract}

The relationship between a Lubrication Mode Diagram (LMD) for concentrated contacts (LCC's) and the 'IRG transition' diagram has been studied. In addition, scuffing results, obtained by the IRG (International Research Group) have been analysed, as well as the results of scuffing tests performed by different workers using a two-disc apparatus.

It has been found that in Region I of the IRG transition diagram, three sub-regions can be distinguished, representing elastohydrodynamic lubrication, mixed lubrication, and boundary lubrication, respectively. Thus, the IRG transition diagram is not comparable to a 'lubrication mode diagram'. Furthermore, it has been found that failure of LCC's by scuffing most frequently occurs under conditions of mixed lubrication. Therefore, scuffing criteria based upon the assumption that the load at failure is carried entirely by the micro-contacts are doubtful, and probably wrong.

Nomenclature
$E$

Equivalent elasticity modulus for combined surfaces

$F_{\text {n }} \quad$ Normal force

$H \quad$ Operational number: $H=\eta_{\mathrm{i}} \cdot V_{+} \sqrt{p}$

$L \quad$ Lubrication number: $L=H / R a_{\mathrm{t}}=\eta_{\mathrm{i}} \cdot V_{+} /\left(\bar{p} \cdot R a_{\mathrm{t}}\right)$

$p \quad$ Mean contact pressure

$R \quad$ Reduced radius of curvature

$R a_{\mathrm{t}}$

$R a_{\mathrm{t}}=\left(R a_{1}{ }^{2}+R a_{2}{ }^{2}\right)^{1 / 2}$

$S \quad$ Slip or slide-to-roll ratio: $S=2 \cdot V_{\mathrm{s}} / V_{+}$

$V_{\mathrm{s}} \quad$ Sliding velocity: $V_{s}=\left|V_{1}-V_{2}\right|$

$V_{+} \quad$ Sum velocity: $V_{+}=V_{1}+V_{2}$

$\eta_{i} \quad$ Inlet viscosity

$\mu \quad$ Coefficient of friction

1,2

refers to properties of individual surfaces
Units

(m) 
D.J. Schipper and A.W.J. de Gee: Lubrication Modes and the IRG Transition Diagram

Figure 1 IRG transition diagram

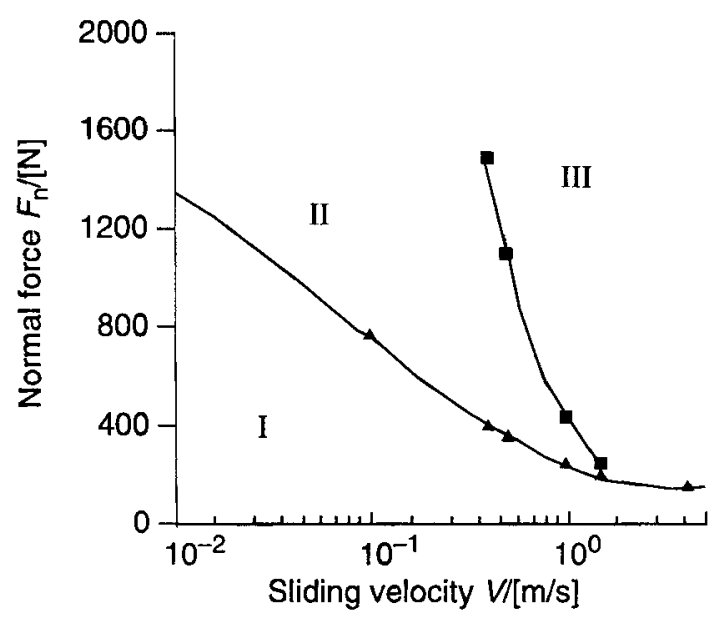

lubrication mode diagram, concentrated contact, IRG transition, EHL, mixed lubrication, BL, load, scuffing

The failure by scuffing of lubricated concentrated contacts (LCC's) has been studied extensively by the International Research Group on Wear of Engineering Materials (IRGOECD). ${ }^{1,2,3}$ The investigations performed by the IRG-OECD group were conducted under conditions of simple sliding, i.e. the sliding velocity equals the sum velocity. The result of this work is a 'Transition Diagram', an example of which is shown in Figure 1. In this diagram, where the load-carrying capacity $F_{\mathrm{n}}$ is presented as a function of the sliding velocity $V_{\mathrm{s}}$, three regions, separated by two transition curves, can be distinguished. These regions are governed by the measured friction time characteristics, see Figure 2. Region I is considered to be a 'safe' region, where friction is low and wear is virtually negligible $(\mu \leq$ 0.1 and wear rate $k \approx 10^{-8} \mathrm{~mm}^{3} / \mathrm{N} \cdot \mathrm{m}$ ). The lubrication condition in this region is often referred to as partial EHL. If the contact is to operate in Region III, it fails almost immediately by scuffing, with $\mu \approx 0.5$ and $k \approx 10^{-3} \mathrm{~mm}^{3} / \mathrm{N} \cdot \mathrm{m}$. In the intermediate Region II, initial values of $\mu \approx 0.35$ and $k \approx 5 \cdot 10^{-6} \mathrm{~mm}^{3} / \mathrm{N} \cdot \mathrm{m}$ occur, both decreasing with time. In references $1,2,3$ and 6 , the influence of a great number of parameters (radius of curvature, viscosity, additives, roughness, etc.) on the transitions is described 
D.J. Schipper and A.W.J. de Gee: Lubrication Modes and the IRG Transition Diagram

Figure 2 Friction-time

curves in Region I, II, and III

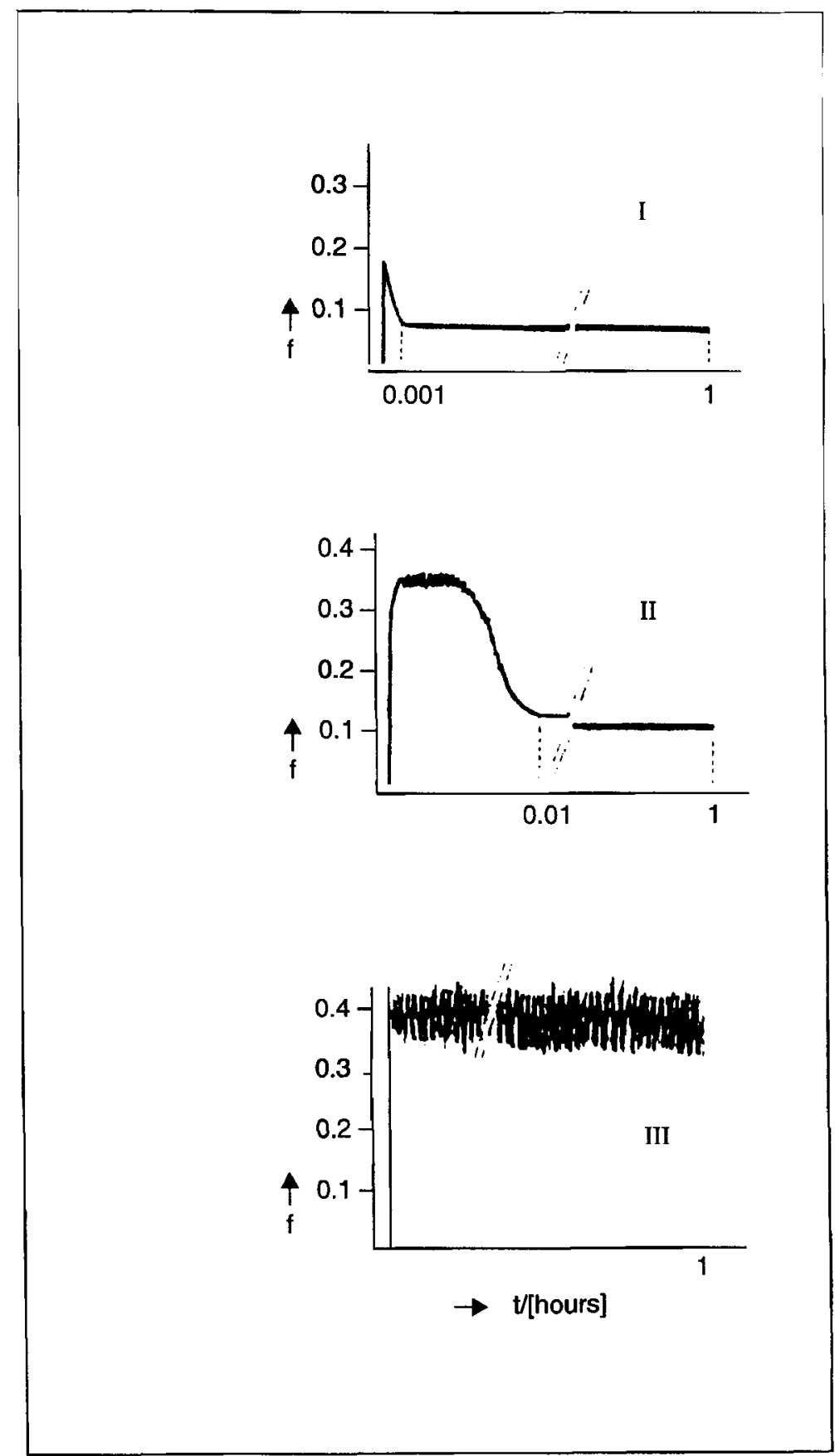

Lubrication Science 8-1, October 1995. (8) $290954-0075 \$ 10.00+\$ 4.00$ 
D.J. Schipper and A.W.J. de Gee: Lubrication Modes and the IRG Transition Diagram

Figure 3 Generalised
Stribeck curve

LUBRICATION MODE DIAGRAM (LMD)

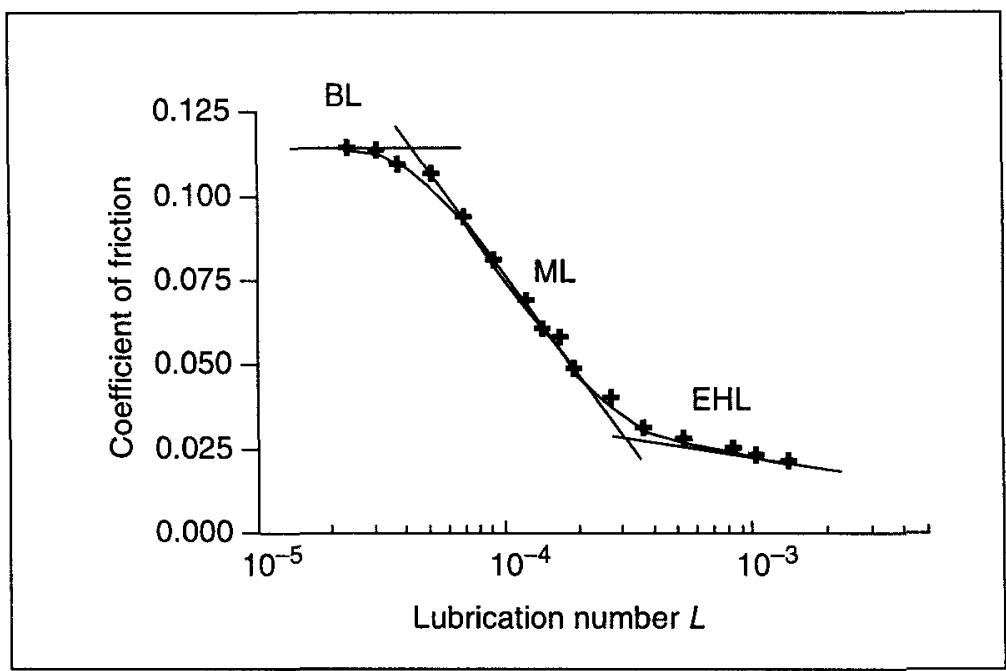

for lubricated AISI-52100 steel contacts. The IRG transition diagram technique has proved its value in comparative testing, i.e. in ranking material combinations, surface treatments or lubricants with respect to load-carrying capacity in concentrated contact situations. ${ }^{8}$ More recently, ${ }^{9,10}$ a 'Lubrication Mode Diagram'(LMD) for LCC's has been developed, from which the lubrication modes, elastohydrodynamic lubrication (EHL), mixed lubrication (ML) and boundary lubrication (BL) can be determined as a function of the operational variables and the relevant element properties. In this paper, Region I is studied in detail with respect to the lubrication modes that may occur, and to determine the mode of lubrication at the moment of scuffing.

In a Stribeck-type diagram as shown in Figure 3, in which the coefficient of friction is shown as a function of a lubrication number $L$, the lubrication modes EHL, ML and BL can be distinguished. The lubrication number $L$ is defined as:

$L=\eta_{\mathrm{i}} \cdot V_{+} /\left(\bar{p} \cdot R a_{\mathrm{t}}\right)=H / R a_{\mathrm{t}}$

On the basis of virtually isothermal friction experiments performed in Region I of the IRG-transition diagram, the transitions from EHL to ML and from ML to $\mathrm{BL}$ were studied as a 
D.J. Schipper and A.W.J. de Gee: Lubrication Modes and the IRG Transition Diagram

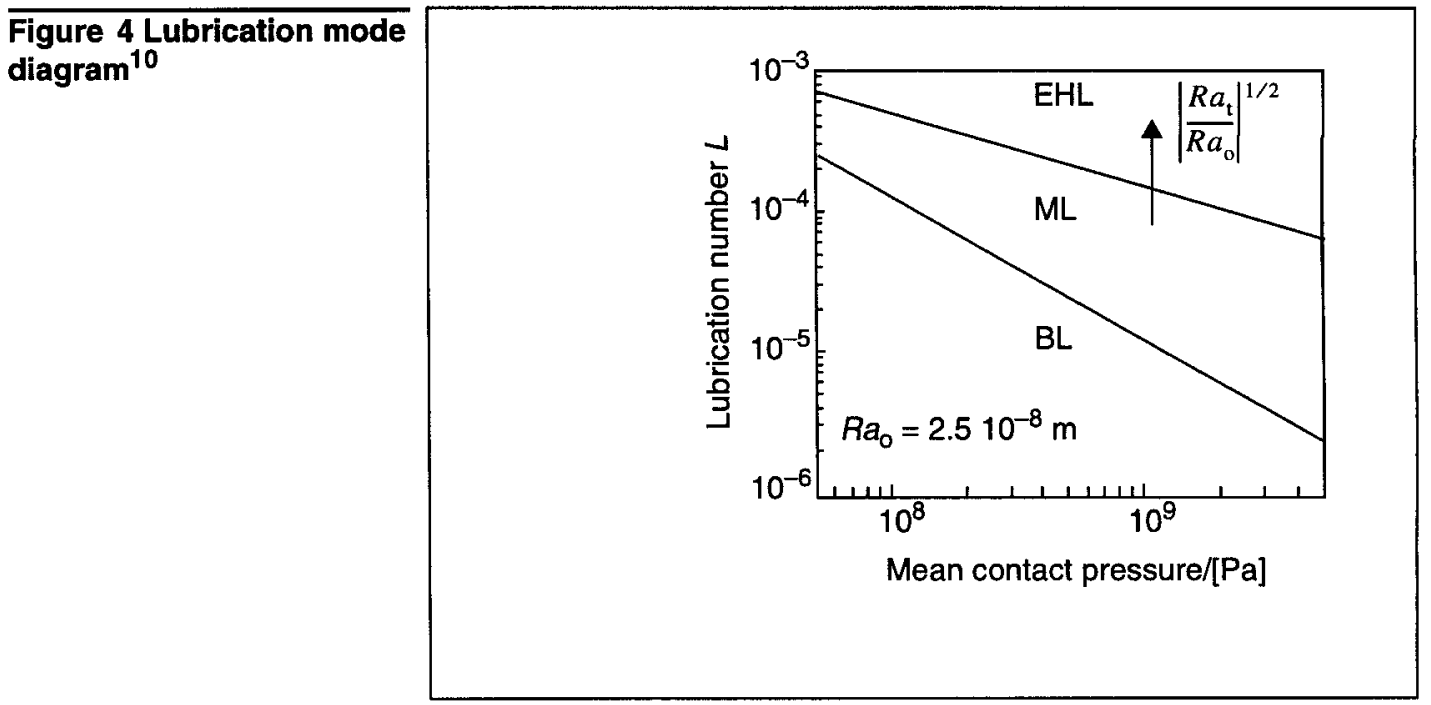

function of the operational variables and the element properties: surface roughness, type of lubricant and material of the surfaces. This study resulted in a LMD as given in Figure 4. It turns out that the EHL-ML and ML-BL transitions can in a general form be described by:

$H / R a \frac{\mathrm{k}}{\mathrm{t}}=l \cdot \overline{\mathrm{p}}^{\mathrm{m}}$

with $k=1.5, l=3.1 \cdot 10^{4}$ and $m \approx-0.5$ for the EHL-ML transition and $k=1, l=1.25 \cdot 10^{4}$ and $m \approx-1.0$ for the ML-BL transition.

LUBRICATION MODES IN REGION I OF THE IRG TRANSITION DIAGRAM
Combining the LMD with the IRG transition diagram will give the lubrication modes that apply in Region I. Rewriting equation (2) in terms of $V_{\mathrm{S}}$ and $\bar{p}$, using $S=2 \cdot V_{\mathrm{s}} / V_{+}, H=\eta_{\mathrm{i}} \cdot V_{+} \sqrt{p}$ and $\bar{p}=\left(3 \cdot F_{\mathrm{n}} \cdot E^{2} / R^{2}\right)^{1 / 3} /(3 \cdot \pi)$ (circular contact), one obtains:

EHL-ML: $\quad V_{\mathrm{s}}=1.55 \cdot 10^{4} \frac{S \cdot R a_{\mathrm{t}}^{\frac{3}{2}} \cdot \bar{p}^{\frac{1}{2}}}{\eta_{\mathrm{i}}}$

$\mathrm{ML}-\mathrm{BL}: \quad V_{\mathrm{s}}=6.25 \cdot 10^{3} \frac{S \cdot R a_{\mathrm{t}}}{\eta_{\mathrm{i}}}$ 
D.J. Schipper and A.W.J. de Gee: Lubrication Modes and the IRG Transition Diagram

\section{Figure 5 Combination of LMD and IRG transition diagram}

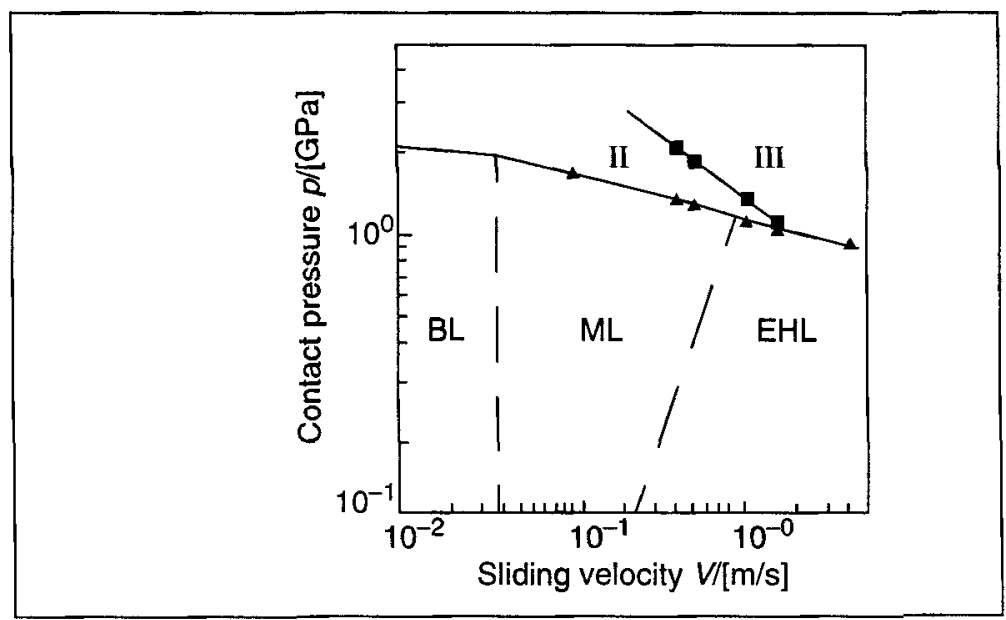

These equations yield transition lines (dashed), as shown in Figure 5, representing EHL-ML and ML-BL in Region I. For $\eta_{\mathrm{i}}$ and $R a_{\mathrm{t}}$, the oil supply temperature and initial surface roughness are used. The transition lines, which are nearly perpendicular to the transitions of the IRG diagram, strongly suggest that Region I of the IRG transition diagram can be subdivided into three subregions, representing EHL, ML and $B L$ respectively. This result shows that the IRG transition diagram is not a LMD as often suggested in the literature.

It also appears that LCC's may fail even when operating under conditions of full-film separation of the surfaces, a proposition that is unlikely to be realistic. The explanation for this apparent discrepancy between the IRG and LMD results is that the conditions during determination of the IRG diagram are by no means iso-thermal, meaning that the temperature at the inlet of the lubricant wedge steadily increases (due to a temperature rise of the contacting bodies near the contact) with increasing load and testing time. As a result, the inlet viscosity of the lubricant steadily decreases, and the EHL-ML as well as the ML-BL transition, shift to (much) higher values of $V_{\mathrm{s}}$, c.f. equations (2) and (3).

Many scuffing experiments were performed on two-disc machines. ${ }^{4,5,7,11}$ In these experiments, sliding velocity and sum velocity could be varied independently. One of the conclusions that can be drawn from the results is that, as in IRG testing, 
D.J. Schipper and A.W.J. de Gee: Lubrication Modes and the IRG Transition Diagram

\begin{tabular}{|c|c|}
\hline $\begin{array}{l}\overline{\text { Fig }} \\
\text { dat: }\end{array}$ & $\begin{array}{l}\text { ure } 6 \text { Two-disc scuffing } \\
\text { a plotted in the LMD }\end{array}$ \\
\hline & $\begin{array}{l}\text { (Bell) } T=76^{\circ} \mathrm{C} \\
S=62.5 \%\end{array}$ \\
\hline$\bullet$ & $\begin{array}{l}\text { (Bell) } T=40^{\circ} \mathrm{C} \\
S=62.5 \%\end{array}$ \\
\hline+ & Lee \\
\hline & $\begin{array}{l}\text { (Bell) } T=76^{\circ} \mathrm{C} \\
S=100 \%\end{array}$ \\
\hline & $\begin{array}{l}\text { (Snidle) } T=76^{\circ} \mathrm{C} \\
S=100 \%\end{array}$ \\
\hline & $\begin{array}{l}\text { (Bell) } T=40^{\circ} \mathrm{C} \\
S=100 \%\end{array}$ \\
\hline
\end{tabular}

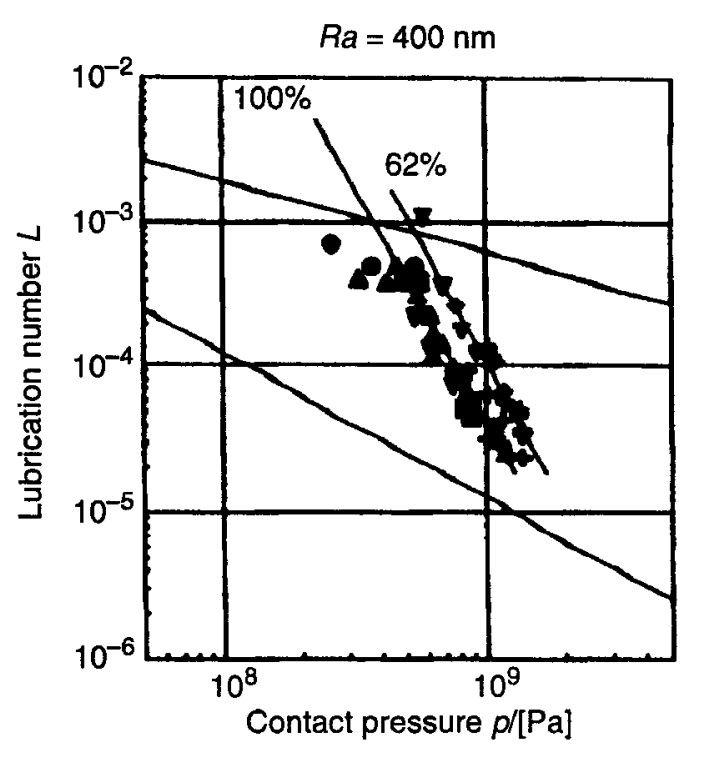

for scuffing to occur, the bulk temperature of the contacting bodies near the contact region plays an important role. The temperature in the contact itself seems to be less important.

If values of the measured bulk temperature are used to determine the inlet viscosity, and if the roughness just before scuffing is taken for $R a_{t}$ one obtains the results shown in Figure 6, in which the scuffing data are plotted in the LMD. From this it can be concluded that, generally, scuffing occurs under ML conditions. Also, in 'IRG-type tests', bulk temperatures just before scuffing were recorded. ${ }^{12}$ Results in LMD terms are shown in Figure 7. Again it is found that scuffing occurs under conditions of $\mathrm{ML}$, as mentioned in reference 1 . The IRG and two-disc scuffing experiments are in rather good agreement when plotted in the lubrication mode diagram using the bulk temperature near the contact.

Figure 8 shows schematically failure by scuffing in the generalised Stribeck curve, the lubricating condition changing quickly from mixed to 'dry' lubrication.

An important consequence of the above is that scuffing criteria, based on the assumption that at the moment of failure the load is entirely carried by micro-contacts, are wrong. Also, scuffing criteria containing a coefficient of friction are 
D.J. Schipper and A.W.J. de Gee: Lubrication Modes and the IRG Transition Diagram

Figure 7 IRG pin-on-disc experiments plotted in the LMD

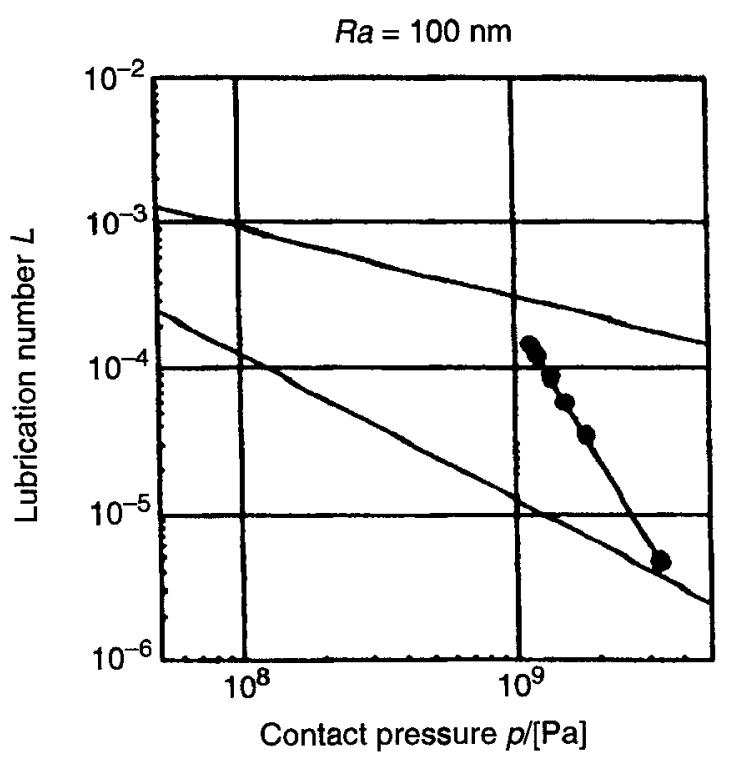

Figure 8 Failure by scuffing $(B)$ in the ML regime, schematically

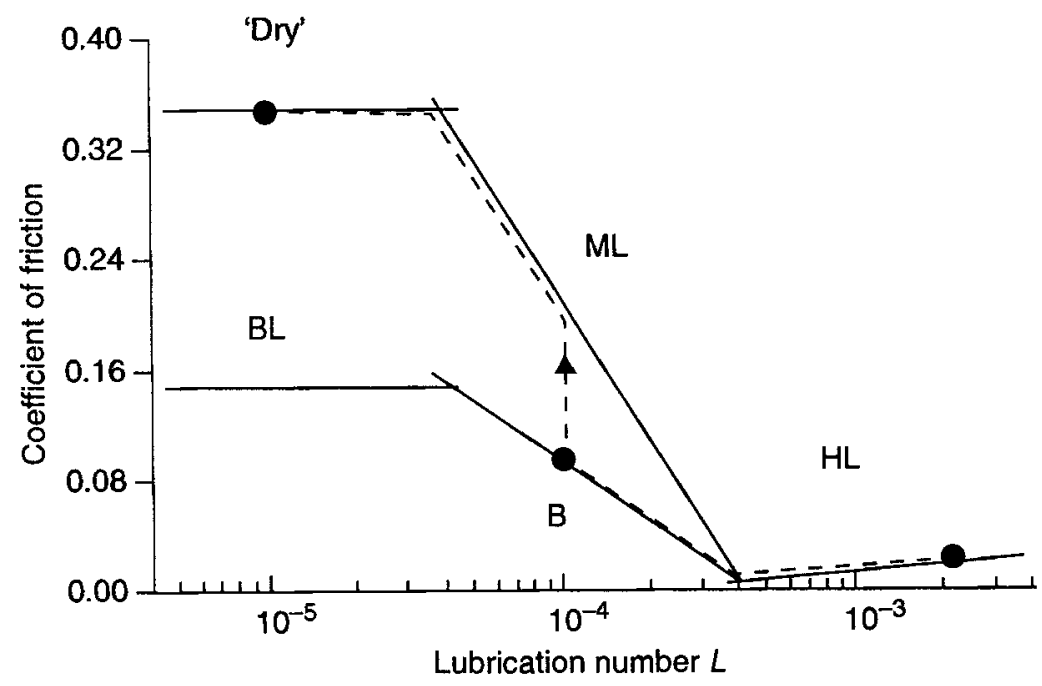

Lubrication Science 8-1, October 1995. (8) $340954-0075 \$ 10.00+\$ 4.00$ 
inadequate, because the value of this parameter is not known a priori. In fact, a simple criterion for predicting failure by scuffing of a lubricated system is not yet available. Instead, one will have to rely upon experimental data of IRG or two disc type.

CONCLUSIONS

(1) In Region I of the IRG transition diagram exist three subregions, representing $\mathrm{EHL}, \mathrm{ML}$ and $\mathrm{BL}$ respectively. The location and size of these subregions change due to running-in and viscosity effects.

(2) The IRG transition diagram as such is not a 'Lubrication Mode Diagram'. It should be regarded and used as a 'Wear Diagram'.

(3) Analysis of scuffing results shows that scuffing frequently, if not exclusively, occurs in the ML-regime. Therefore, scuffing criteria based upon the assumption that, at failure, the entire load is carried by micro-contacts, are doubtful and probably wrong.

1. Begelinger, A., and Gee, A.W.J. de, ASME Jnl. of Lubr. Tech., 98, 575 (1976).

2. Gee, A.W.J. de, et al., Proc. Int. Conf. on Wear of Materials, Reston, Va., USA, ed. K.C. Ludema, ASME, New York, 1983, p. 534.

3. Gee, A.W.J. de et al., Proc. 11th Leeds-Lyon Symposium on Tribology, Leeds, Butterworth, London, 1985, p. 105.

4. Bell, J.C., and Dyson, A., Second Symposium on Elastohydrodynamic Lubrication, Leeds, England, Inst. Mech. Engrs., 1972, C11/72 and C12/72.

5. Bell, J.E., et al., ASLE Trans., 18, 62 (1975).

6. Czichos, H., Tribology, 7, 14-20 (1974).

7. Lee, S.C., Ph.D. Thesis, University of Illinois at Chicago, USA, 1989.

8. Lossie, C.M., et al., Wear, 129, 173 (1989).

9. Schipper, D.J., Ph.D. Thesis, Twente University, The Netherlands, 1988.

10. Schipper, D.J., et al., Eurotrib '89, Helsinki, Finland, 1989, p. 171.

11. Snidle, R.W., et al., Proc. R. Soc. Lond., Vol. A 395, 1984, pp. 291-311.

12. Schipper, D.J., unpublished results. 